\title{
Redefining Landscape Structure for Ecosystem Services
}

\author{
Felix Eigenbrod ${ }^{1}$
}

Published online: 15 August 2016

(C) The Author(s) 2016. This article is published with open access at Springerlink.com

\begin{abstract}
Our understanding of the effects of landscape structure on ecosystem services (ES) remains at a very early stage, despite a large body of literature on the effects of the composition and configuration of natural land cover on some ES. Here, I argue that a comprehensive understanding of the effects of landscape structure on ES requires us to reconsider what constitutes landscape structure for ES. Such reconsideration requires us to re-visit John Wiens' idea that for biodiversity, a landscape and its structure are organism- and question- dependent and apply this idea to ES by redefining landscape structure for ES to include not only land cover, but also other social and biophysical drivers of ES. The underlying reason for this is that ES are products of coupled socio-ecological systems and therefore do not only depend on ecological processes and/or distributions of key species, but also on social and biophysical variables. As a result, for many ES, relevant landscape structure will not only include features traditionally considered by ecologists, such as natural land cover, but also the amount and configuration of social variables, such as land management systems and distributions of wealth and human populations. Obtaining a general understanding of how landscape structure affects ES is vital if we are to manage landscapes effectively to ensure sustainable supplies of ES now and into the future.
\end{abstract}

Keywords Fragmentation - Habitat amount .

Socio-ecological systems $\cdot$ Configuration $\cdot$ Composition $\cdot$

Natural capital

This article is part of the Topical Collection on Effects of Landscape Structure on Human Wellbeing

Felix Eigenbrod

f.eigenbrod@soton.ac.uk

1 Biological Sciences, University of Southampton, Highfield Campus, Southampton SO17 1BJ, UK

\section{Introduction}

Over 25 years ago, John Wiens first argued that a useful way to think about the size of landscapes and their structure (composition and configuration) is to consider both landscape size and structure to be organism- and question-dependent [1, 2]. In practical terms, this means that the spatial scale of studies should match that at which organisms perceive and/or interact with their environment. For example, for a forest beetle, relevant landscape structure might be the amount of deadwood and leaf cover within a 2-m radius of a 'focal patch' sampling point [3], while for a leopard frog, relevant landscape structure might include the amount of forest cover and amount of roads within $2000 \mathrm{~m}$ of a 'focal patch' sampling point (Fig 1) [4]. The spatial scale of studies needs to be question dependent as organisms may interact with different components of the landscapes at different scales at different stages in their life history. For example, long-distance dispersal for wood thrush can lead to interactions with the landscape at scales of 60-80 km [5], while landscapescale factors that affect juvenile survival rates of this species are likely to be affected by much smaller-scale processes.

These seminal papers by Wiens led to a major research effort in landscape ecology to understand the general effects of landscape structure on biodiversity. Four major conclusions have emerged from this work [6]: (1) the effects of loss of natural habitat (a composition effect) usually have strongly negative effects on biodiversity; (2) the effects of fragmentation of natural habitat (a configuration effect) can be both positive and negative; (3) the effects of habitat loss generally exceed the effects of habitat fragmentation [7-9]; (4) the quality (or lack thereof) of non-habitat elements of the landscape (matrix) can have major positive and negative effects on biodiversity (e.g. [10]).

Whilst a synthetic understanding has been attained for the effects of landscape structure on biodiversity, no such general understanding of the effects of landscape structure on ES as yet 
exists $[11,12]$, despite the enormous interest in ES by both the scientific community and policy-makers [13]. This lack of consensus is likely due in part to the fact that the effects of landscape structure on ES are much more variable than those of biodiversity [12]. The reason for this is that ES are products of coupled social-ecological systems [14], and as such their distribution is determined by both biophysical and social factors [12]. Obtaining a general understanding of how landscape structure affects ES is vital if we are to effectively manage landscapes to ensure sustainable supplies of ES now and into the future [12].

In this paper, I first give an overview of the current state of knowledge in our understanding of how landscape structure affects ES. I then argue that what is required to make real progress in this field is for us to redefine landscape structure for ES to encompass more than just land cover and also include the spatial distributions of other biophysical and social drivers of ES. I then outline the rationale for this argument, how this research agenda can be operationalized and the challenges that this approach entails.

\section{The Effects of Landscape Structure on Individual ES}

There is a large body of literature on the effects of landscape structure on individual ES; however, not all types of services (regulating, cultural and provisioning) are equally well-represented. There is a particular focus on regulating services, likely because the delivery of these can be most explicitly linked to natural land cover and the biodiversity associated with it [11]. Natural land cover is defined here as land cover not dominated by human activity. Pollination services (for recent reviews, see, for example, [15] and [16]) and pest regulation services (for a recent review, see, for example, [17]) are the two types of regulating services mostly highly represented in the literature. For these two services, most-but not all (e.g. [18]) - studies suggest that the effects of the loss and fragmentation of natural land cover are - as for biodiversity-overwhelmingly negative. The loss and fragmentation of natural land cover also generally appear to have negative effects on climate regulation services (carbon stocks) (e.g. [19, 20]), but for hydrological services the effects of the structure of natural land cover are rather more complex (see [21] for a recent discussion). Much less is known for cultural ES, but the studies that do exist on this subject indicate that the relationship between the structure of natural land cover in the landscapes is highly context specific (e.g. [22]). Interestingly, provisioning $\mathrm{ES}$, which are not directly linked to natural land cover (e.g. agricultural production), are not usually considered individually in studies looking at the effects of landscape structure on ES, but rather in the context of tradeoffs with ES that are related to natural land cover (e.g. [20, 23, 24]). This is possibly a reflection of the conservation biology-focused nature of most ES landscape ecological studies.

\section{The Effects of Landscape Structure on Multiple ES}

Studies that simultaneously examine multiple ES are required for gaining a general understanding of the effects of landscape structure on ES, as different ES do not occur in isolation in landscapes, but rather as bundles of services (suites of co-occurring ES; sensu [25]). As the sign of the relationships between different ES - and hence the composition of bundles of ES - is context-specific [25, 26], synthesizing the results of multiple single ES studies does not necessarily enable an understanding of how changing landscape structure in a region will affect policy-relevant tradeoffs between ES [13]. However, very few studies to date examine the effects of landscape structure on multiple ES at once, nor how landscape structure affects the distribution of ES bundles [11]. The reason for this gap in the literature is likely due to the difficulties in obtaining data on most ES: most ES mapping studies only consider a few ES and focus disproportionately on 'easy- to-map' regulating and provisioning services such as agricultural production and carbon storage [27]. The work that does exist shows that once multiple ES are considered, patch size of natural land cover (which is related to both the amount and configuration at the landscape scale [7]) has both positive and negative effects on ES [24, 28]. Patch isolation (also related to both amount and configuration [7]) also has been shown to have positive and negative effects on ES [24].

\section{Predicting the Effects of the Structure of Natural Land Cover on ES}

There has also been surprisingly little work setting out explicit, empirically based predictions about how landscape structure is most likely to affect ES. Such work is vital as it provides a framework for hypotheses to be tested. The utility of this approach is illustrated by important recent modelling and conceptual work by Mitchell and co-authors $[12,29]$, who predict that once a wide variety of ES in a region are considered at once, the highest levels of ES delivery will occur in landscapes with intermediate amounts and fragmentation of natural habitat. The reason is that delivery of ES depends on the capacity of the ecosystem to supply a particular ES as well as the demand for and flow to particular human beneficiaries of this ES [12, 30]. As result, for many ES (e.g. pollination, pest control, recreation, water filtration), ES delivery can only occur if there is some juxtaposition of natural and non-natural land cover, and such a juxtaposition can only occur if there is some loss and fragmentation of natural land cover [12, 29]. The key conceptual framework that outlines these ideas [12] was criticized for failing to account for the effects of non-natural land cover types and subsequently extended to account for the potential positive effects of fragmentation [31]. However, this useful critique also demonstrates the strength of Mitchell et al.'s framework [12] — it provides a much-needed set of explicit hypotheses on the effects of the amount and configuration of land cover on ES that can be built on and explicitly tested. 


\section{Redefining Landscape Structure for ES-Moving Beyond Land Cover}

It is now widely recognized that ES are co-produced by both social and ecological systems $[32,33]$ and that this coproduction is what drives the distributions of bundles of ES in the landscape [25, 34]. It therefore follows that the distributions of ES in the landscapes will not only depend on the amount and configuration of natural land cover types in the landscape that underpin the biodiversity associated with ES, but also on the spatial distribution of other biophysical drivers as well as a variety of social and cultural drivers. Meacham et al. [32] provide the first test of the relative importance of land cover as compared with three other types of models of human impact (ecological modernization, human footprint and location theory) in predicting the distributions of multiple ES (16 ES in 62 municipalities in southcentral Sweden). Ecological modernization was characterized as the percentage of adults with secondary education and the per capita differences between assets and debts, human footprint was measured by human population density and income, while location theory was measured by distance to the nearest large urban centre (Stockholm) as well as the average slope of each municipality. Meacham et al. [32] show that while land use was the best predictor for most ES, this was not always the case. For example, location theory was the best predictor of phosphorus and nitrogen retention in the landscape, although it had low predictive power overall.

A comprehensive understanding of how landscape structure affects ES clearly requires explicit consideration of additional biophysical, social and cultural drivers as well as land cover in landscape-scale studies. As different ES operate at different spatial scales [35, 36], it is clear that the spatial scale at which these drivers operate will also vary widely, both within and between ES. I argue that a good approach by which to achieve such a comprehensive, scale-aware understanding of spatial structure on ES is to use the hypothesis-focused, organism-centric approach to landscape ecology espoused by John Wiens [1,2], but to make it more suitable for ES research by reconsidering and redefining what constitutes landscape structure for ES. Such reconsideration requires us to re-visit John Wiens' idea that for biodiversity, a landscape and its structure are organism- and question-dependent and apply this idea to ES by considering what constitutes landscape structure not only for the biophysical supply of ES but also for societal demand for ES. This redefinition of landscape structure means that for many ES, relevant landscape structure will not only include features traditionally considered by ecologists, such as natural land cover, but also the amount and configuration of social variables, such as those considered by Meacham et al. [32] (e.g. distributions of wealth and human populations), as well as other features (view points, sacred groves or landmarks) that affect how people interact with the environment. There are four steps to conducting a landscape-scale ES study based on this broader definition of landscape structure.
Step 1: Identify the relevant spatial drivers of different ES in different locations Getting this step right is vital, as it is the configuration and composition of these spatial drivers that will define the spatial structure of the landscape for different ES. Several papers have attempted to identify which social and ecological variables underpin key ES, including a fairly comprehensive expert-based assessment for Europe [37]. Recent work by Jones et al.[38] conceptualizing the stocks and flows of the different 'capitals' that underpin different ES provides a particularly useful framework for systematically identifying both which drivers need to be considered for different ES and the spatial scales at which they operate. These authors provide worked examples of how natural capital interacts with the five human-derived 'capitals' (produced, human, social, cultural and financial) to result in potential supplies of ES, demand for ES, and flows of ES. For example, the realized cultural service of recreational walking in the countryside (which can be quantified as the number of walkers/year in a given location) is a result of an interaction of the potential service and demand for this service by users of it (i.e. walkers). The realized service only occurs if there is flow between supply and demand: this flow is dependent on the quality of produced capital (transport infrastructure) available. The demand is partly dependent on the cultural and social capital, as this determines the degree to which recreational walking is a popular recreational activity, as well as the numbers of people present. The potential service is a product of natural capital (climate, the amount and configuration of different types of land cover, average slope etc.), but also of produced capital, such as car parks, footpaths and bridges [38]. This approach - if systematically applied to other ES - should prove very useful in coming up with a priori potential spatial drivers of ES that go beyond the key species or ecosystem service providers [39] that have been traditionally considered in studies looking at the effects of landscape structure on ES. It is important to note that these different drivers of ES - quantified as components of spatial structure - are likely to vary considerably among locations.

Step 2: Identify the appropriate spatial scale at which each component of spatial structure is likely to affect the distributions of ES In 'ecological' landscape ecology, this step is based on the organism and question of interest, but the situation is more complicated for ES, as there are several components (analogous to organisms) of interest. This is because some elements of spatial structure will affect the biophysical supply of an ES, which is likely to be affected both by aspects of biodiversity and by other biophysical factors, while others will affect the demand for the ES, which is determined by the human beneficiaries of the service. It is important to note that different socio-economic groups have different needs for different ES [40] and that landscape spatial structure will not affect the distribution of the beneficiaries of climate regulating services due to the global nature of the beneficiaries for this group of ES 
[35]. The relevant spatial scale(s) of the study will also be affected by the question being asked, which for ES needs to have management relevance. A key consideration here is the spatial extent of the sampling location (the focal patch). In landscape ecology, a focal patch is usually a discrete area of habitat relevant to an organism of interest (e.g. a pond for amphibians), while in an ES study, the size of the 'focal patch' might most sensibly align with political boundaries (e.g. municipalities [32, 34]) as these are the scale at which decisions are made. For example, a management-relevant question might be to determine how landscape structure affects the realized recreational walking potential of different nature reserves (or parks) in a region (Fig. 1). In this example, factors such as the amount and configuration of natural land cover, aspect and viewpoints both within and possibly just outside each reserve are likely to affect the potential supply of the service. By contrast, the demand for the service will depend mostly on the number of recreational walkers that live with easy travelling distance of the reserve; this will in turn depend on the socio-economic make-up of the walkers as well as the amount and configuration of the transportation infrastructure that links the reserve to the potential walkers. In many cases, the 'best' spatial scale for a variable will not be known; in this case the analyses need to be conducted at multiple spatial scales as is commonplace in landscape ecology. Importantly, a 'classical' ecological landscape study will often need to be part of a ES landscape ecological study, as the potential supply of many ES is at least partially dependent on the distribution of key components of biodiversity [41].
Step 3: Identity spatial datasets for each of the relevant components of spatial structure Identifying such spatial datasets is a non-trivial challenge, as many social variables, such as census data, are only available at the level of political boundaries (e.g. municipalities), which means that looking at the effects of the configuration of such variables within municipalities is difficult. However, the rapid recent advances in remote sensing (reviewed in [42]) as well as newly available high-resolution gridded data on human populations (e.g. [43]) mean that examining both configuration and composition effects of ecological, biophysical and social variables will become easier in the near future.

Step 4: Test the relative predictive power of these different components of landscape structure for different ES Such tests should be carried out for different ES in different locations to identify the degree of generality in the importance of different components of spatial structure. For some ES, such as recreational value of the countryside, such studies might already be possible using existing data. For example, while there is no study to date that has explicitly considered the different drivers of recreational walking outlined earlier in terms of the relative contribution of different elements of landscape structure, there are many case studies that have statistically examined the relative importance of spatial drivers of recreational use of the countryside (e.g. [22, 44]). In some cases, such datasets could be re-analysed by explicitly quantifying the composition and configuration of these drivers of recreation at multiple spatial scales, thereby enabling the



a

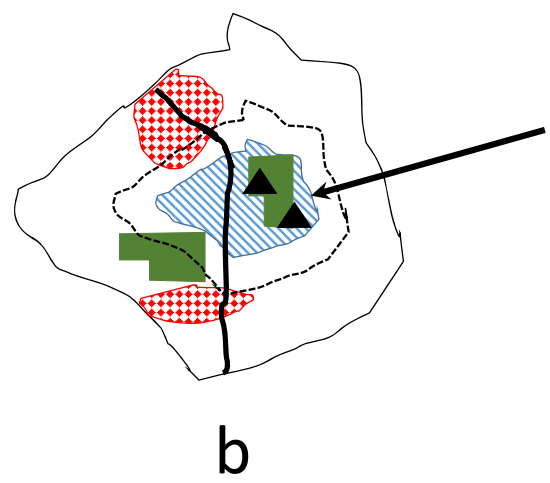

Fig. 1 A simple example of a landscape ecological study design for an 'ecological' (a) and ecosystems services (ES; b) question. In the 'ecological' example (a), the organisms of interest are leopard frogs, and the 'focal patch' [3] where they are sampled are small ponds (open circle with diagonal blue lines and a black arrow pointing to it). The relevant scale here is a 2000-m radius from the edge of the pond [4], and the relevant components of landscape structure are the amount and configuration of forest (solid dark-green blocks) and roads (solid black lines) in each landscape. In the ES example (b), the service of interest is the realized value of recreational walking. The focal landscapes here are nature reserves (area marked with diagonal blue lines and a black arrow pointing to it) as this is a scale that is of relevance to management; it is within these reserves that recreational walking needs to be quantified, based on numbers of walkers or some other metric, such as time spent

walking. The relevant spatial structure for the potential supply of this ES might include the amount and configuration of features such as forest cover (dark-green blocks) and viewpoints (black triangles), both within each reserve but also just outside the reserve but within its viewshed (area outlined by dashed black line). The demand for this ES needs to be quantified at a larger spatial scale (area outlined by solid black lines) than the potential supply because the relevant spatial structure for this component of the ES will include the amount and distribution of urban areas (areas outlined by solid red line and marked with red diamonds) within 'easy' travelling distance (which will be context dependent), but also the amount and configuration of the road infrastructure (solid thick black lines). In addition, the interaction between urban areas, viewpoints and road infrastructure is likely to be an important predictor of demand 
effects of landscape structure to be explicitly addressed at multiple spatial scales for this ES.

However, as noted earlier, studies of individual ES are in themselves insufficient to understand how landscapes need to be managed to provide the multiple ES required of them. The Swedish study of Meacham et al. [32] discussed earlier herein which quantifies the relative importance of four types of models of human impact for predicting multiple ES can be thought of as the first landscape ecological study of a more widely defined landscape 'structure' (in this case composition only) on multiple ES as it is carried out at a scale relevant to management (municipality). More studies like this are required to truly understand how this wider definition of landscape structure affects ES in different regions globally.

The greatest progress in understanding the wider effects of landscape structure on ES will come if ES science learns from the experience of ecologists designing landscape-scale studies looking at the impacts of spatial structure on biodiversity. McGarigal and Cushman's [45] guidelines for how to conduct research on fragmentation are as relevant now as when they were first published in 2002. A major issue will be that of covariation of putative predictor variables, which can lead to masking of the effects of one variable (e.g. roads) by another (e.g. forest cover) [46]. Care must also be taken to ensure that metrics that supposedly measure configuration (e.g. fragmentation) are not also correlated with composition [7]. This latter challenge is likely to prove even more difficult for ES studies than for ecological ones, given the larger number of predictor variables that are involved in ES studies, and the fact that in ES studies social and ecological variables are frequently correlated and interactions between variables are likely. Given the major logistic challenges of designing empirical landscape ecological ES studies, much more modelling work is required to develop more in-depth hypotheses on the effects of landscape structure on ES. Such work should build on seminal neutral landscape modelling of the effects of habitat loss and fragmentation on biodiversity in landscape ecology (e.g. [47, $48]$ ) and on recent work on the effects of natural land cover on ES [29] using a similar approach.

\section{Summary}

Our understanding of the effects of landscape structure on ES remains at a very early stage, despite a large body of literature looking at the effects of the composition and configuration of natural land cover on some ES. We are only beginning to quantify the spatial patterns of ES using landscape ecological metrics (e.g. [49, 50]), and the work by Mitchell et al. [12] outlined earlier represents the first real attempt to develop a theoretical framework of our expectations of how natural land cover will affect ES. I argue here that in addition to testing the hypotheses outlined by Mitchell et al.[12] on the effects of the structure of natural land cover on ES, we also need to start explicitly analysing how other components of landscape structure-including social drivers - affect the distributions of ES. The advantage of the landscape ecological study design I advocate here, namely to consider both biophysical and social predictors of ES, over existing approaches is that the former enables the investigator to explicitly and systematically examine the relative importance of different spatial predictors of different ES at appropriate spatial scales. Whilst finding landscapes that enable good landscape-scale studies of ES to be designed will likely prove challenging in many cases, engaging in the process of designing such studies and testing them in simple model systems are still important areas of research. This is because thought experiments and simple models that are based on the landscape-scale study design I advocate here should help to enable the development of more focused hypotheses on how different spatial components of the socio-ecological system combine at different spatial scales to produce ES. Given the widely recognized importance of scale for ES [36, 51], a combination of theoretical, modelling and empirical landscapescale ES research should help to enable a better understanding of the importance of the different spatial processes in driving the distributions of ES on which we all depend.

Acknowledgements Many thanks to Rebecca Spake and two anonymous reviewers for their insightful comments on earlier versions of this manuscript.

Compliance with Ethical Standards

Conflict of Interest The author states that there is no conflict of interest.

Human and Animal Rights and Informed Consent No animals or human subjects were used for this research.

Open Access This article is distributed under the terms of the Creative Commons Attribution 4.0 International License (http:// creativecommons.org/licenses/by/4.0/), which permits unrestricted use, distribution, and reproduction in any medium, provided you give appropriate credit to the original author(s) and the source, provide a link to the Creative Commons license, and indicate if changes were made.

\section{References}

1. Wiens JA, Milne BT. Scaling of "landscapes" in landscape ecology, or, landscape ecology from a beetle's perspective. Landsc Ecol. 1989;3:87-96.

2. Wiens JA. Spatial scaling in ecology. Funct Ecol. 1989;3:385-97.

3. Tischendorf L, Fahrig L. On the usage and measurement of landscape connectivity. Oikos. 2000;1:7-19.

4. Eigenbrod F, Hecnar SJ, Fahrig L. The relative effects of road traffic and forest cover on anuran populations. Biol Conserv. 2008;141: $35-46$. 
5. Tittler R, Fahrig L, Villard MA. Evidence of large-scale source-sink dynamics and long-distance dispersal among wood thrush populations. Ecology. 2006;87:3029-36.

6. Gagné SA, Eigenbrod F, Bert DG, Cunnington GM, Olson LT, Smith AC, et al. A simple landscape design framework for biodiversity conservation. Landsc Urban Plan. 2015;136:13-27.

7. Fahrig L. Effects of habitat fragmentation on biodiversity. Annu Rev Ecol Evol Syst. 2003;34:487-515.

8. Villard MA, Metzger JP. Beyond the fragmentation debate: a conceptual model to predict when habitat configuration really matters. J Appl Ecol. 2014;51:309-18.

9. Ewers RM, Didham RK. Confounding factors in the detection of species responses to habitat fragmentation. Biol Rev Camb Philos Soc. 2006;81:117-42.

10. Kupfer JA, Malanson GP, Franklin SB. Not seeing the ocean for the islands : the mediating influence of matrix-based processes on forest fragmentation effects. Glob Ecol Biogeogr. 2006;15:8-20.

11. Mitchell MGE, Bennett EM, Gonzalez A. Linking landscape connectivity and ecosystem service provision: current knowledge and research gaps. Ecosystems. 2013;16:894-908.

12. Mitchell MGE, Suarez-Castro AF, Martinez-Harms M, Maron M, McAlpine C, Gaston KJ, et al. Reframing landscape fragmentation's effects on ecosystem services. Trends Ecol Evol. 2015;30: 190-8.

13. Wong CP, Jiang B, Kinzig AP, Lee KN, Ouyang Z. Linking ecosystem characteristics to final ecosystem services for public policy. Ecol Lett. 2015;18:108-18.

14. Carpenter SR, Mooney HA, Agard J, et al. Science for managing ecosystem services: beyond the millennium ecosystem assessment. Proc Natl Acad Sci USA. 2009;106:1305-12.

15. Hadley AS, Betts MG. The effects of landscape fragmentation on pollination dynamics: absence of evidence not evidence of absence. Biol Rev. 2012;87:526-44.

16. Kennedy CM, Lonsdorf E, Neel MC, et al. A global quantitative synthesis of local and landscape effects on wild bee pollinators in agroecosystems. Ecol Lett. 2013;16:584-99.

17. Rusch A, Chaplin-Kramer R, Gardiner MM, et al. Agricultural landscape simplification reduces natural pest control: a quantitative synthesis. Agric Ecosyst Environ. 2016;221:198-204.

18. Brosi BJ, Armsworth PR, Daily GC. Optimal design of agricultural landscapes for pollination services. Conserv Lett. 2008;1:27-36.

19. Ziter C, Bennett EM, Gonzalez A. Functional diversity and management mediate aboveground carbon stocks in small forest fragments. Ecosphere. 2013;4:art85. doi: 10.1890/ES13-00135.1

20. Chaplin-Kramer R, Sharp RP, Mandle L, et al. Spatial patterns of agricultural expansion determine impacts on biodiversity and carbon storage. Proc Natl Acad Sci USA. 2015;112:7402-7.

21. Qiu J, Turner MG. Importance of landscape heterogeneity in sustaining hydrologic ecosystem services in an agricultural watershed. Ecosphere. 2015;6:art229.

22. van Zanten BT, Zasada I, Koetse MJ, Ungaro F, Häfner K, Verburg $\mathrm{PH}$. A comparative approach to assess the contribution of landscape features to aesthetic and recreational values in agricultural landscapes. Ecosyst Serv. 2016;17:87-98.

23. Grêt-Regamey A, Rabe SE, Crespo R, Lautenbach S, Ryffel A, Schlup B. On the importance of non-linear relationships between landscape patterns and the sustainable provision of ecosystem services. Landsc Ecol. 2014;29:201-12.

24. Mitchell MGE, Bennett EM, Gonzalez A. Forest fragments modulate the provision of multiple ecosystem services. J Appl Ecol. 2014;51:909-18.

25. Bennett EM, Peterson GD, Gordon LJ. Understanding relationships among multiple ecosystem services. Ecol Lett. 2009;12:1394 404.

26. Anderson BJ, Armsworth PR, Eigenbrod F, Thomas CD, Gillings $\mathrm{S}$, Heinemeyer A, et al. Spatial covariance between biodiversity and other ecosystem service priorities. J Appl Ecol. 2009;46:888-96.
27. Crossman ND, Burkhard B, Nedkov S, et al. A blueprint for mapping and modelling ecosystem services. Ecosyst Serv. 2013; 4:4 14.

28. Cordingley JE, Newton AC, Rose RJ, Clarke RT, Bullock JM. Habitat fragmentation intensifies trade-offs between biodiversity and ecosystem services in a heathland ecosystem in southern England. PLoS ONE. 2015;10:e0130004.

29. Mitchell MGE, Bennett EM, Gonzalez A. Strong and nonlinear effects of fragmentation on ecosystem service provision at multiple scales. Environ Res Lett. 2015;10:094014.

30. Villamagna AM, Angermeier PL, Bennett EM. Capacity, pressure, demand, and flow: a conceptual framework for analyzing ecosystem service provision and delivery. Ecol Complex. 2013;15:114 21.

31. Andrieu E, Vialatte A, Sirami C. Misconceptions of Fragmentation's effects on ecosystem services: a response to Mitchell et al. Trends Ecol Evol. 2015;30:633-4.

32. Meacham M, Queiroz C, Norström AV, Peterson GD. Socialecological drivers of multiple ecosystem services: what variables explain patterns of ecosystem services across the Norrström drainage basin? Ecol Soc. 2016;21(1):14.

33. Reyers B, Biggs R, Cumming GS, Elmqvist T, Hejnowicz AP, Polasky S. Getting the measure of ecosystem services: a socialecological approach. Front Ecol Environ. 2013;11:268-73.

34. Raudsepp-Hearne C, Peterson GD, Bennett EM. Ecosystem service bundles for analyzing tradeoffs in diverse landscapes. Proc Natl Acad Sci USA. 2010;107:5242-7.

35. Hein L, van Koppen K, de Groot RS, van Ierland EC. Spatial scales, stakeholders and the valuation of ecosystem services. Ecol Econ. 2006;57:209-28.

36. Scholes R, Reyers B, Biggs R, Spierenburg M, Duriappah A. Multiscale and cross-scale assessments of social-ecological systems and their ecosystem services. Curr Opin Environ Sustain. 2013;5:1625

37. Kienast F, Bolliger J, Potschin M, de Groot RS, Verburg PH, Heller I, et al. Assessing landscape functions with broad-scale environmental data: insights gained from a prototype development for Europe. Environ Manag. 2009;44:1099-120.

38. Jones L, Norton L, Austin Z, et al. Stocks and flows of natural and human-derived capital in ecosystem services. Land Use Policy. 2016;52:151-62.

39. Kremen C. Managing ecosystem services: what do we need to know about their ecology? Ecol Lett. 2005;8:468-79.

40. Daw T, Brown K, Rosendo S, Pomeroy R. Applying the ecosystem services concept to poverty alleviation: the need to disaggregate human well-being. Environ Conserv. 2011;38:370-9.

41. Cardinale BJ, Duffy JE, Gonzalez A, et al. Biodiversity loss and its impact on humanity. Nature. 2012;486:59-67.

42. de Araujo Barbosa CC, Atkinson PM, Dearing JA. Remote sensing of ecosystem services: a systematic review. Ecol Indic. 2015;52:430-43.

43. Sorichetta A, Hornby GM, Stevens FR, Gaughan AE, Linard C, Tatem AJ. High-resolution gridded population datasets for Latin America and the Caribbean in 2010, 2015, and 2020. Sci Data. 2015;2:150045.

44. Kienast F, Degenhardt B, Weilenmann B, Wäger Y, Buchecker M. GIS-assisted mapping of landscape suitability for nearby recreation. Landsc Urban Plan. 2012;105:385-99.

45. McGarigal K, Cushman SA. Comparative evaluation of experimental approaches to the study of habitat fragmentation effects. Ecol Appl. 2002;12:335-45.

46. Eigenbrod F, Hecnar SJ, Fahrig L. Sub-optimal study design has major impacts on landscape-scale inference. Biol Conserv. 2011;144:298-305.

47. With KA, King AW. Extinction thresholds for species in fractal landscapes. Conserv Biol. 1999;13:314-26. 
48. Fahrig L. How much habitat is enough? Biol Conserv. 2001;100: 65-74.

49. Zhang Z, Gao J. Linking landscape structures and ecosystem service value using multivariate regression analysis: a case study of the Chaohu Lake Basin, China. Environ Earth Sci. 2016;75:1-16.
50. Qiu J, Turner MG. Spatial interactions among ecosystem services in an urbanizing agricultural watershed. Proc Natl Acad Sci USA. 2013;2013:12149-54.

51. Grêt-Regamey A, Weibel B, Bagstad K, Ferrari M, Geneletti D, Klug $\mathrm{H}$, et al. On the effects of scale for ecosystem services mapping. PLoS One. 2014;1-26. 